\title{
OS ENTRAVES (DA TESE) DO FEUDALISMO
}

\section{Érico Alberto de A. Miranda *}

Em seu ensaio "Modos de Produção no Brasil", presente na coletânea organizada por José Roberto do A. Lapa - MODOS DE PRODUÇÃO E REALIDADE BRASILEIRA - Vozes, 1980 -.., Nelson Werneck Sodré reafirma as formulações contidas no seu livro Formação Histórica do Brasil e não considera que as criticas que the foram dirigidas em todos esses anos tenham argumentos suficientes para rever aquelas teses. Amparado unicamente pelo método marxista, parte para a discussão, distinguindo de imediato algumas particularidades que se colocam na análise teórica do caso brasileiro feita agora nesse seu escrito mais recente.

Em primeiro lugar, haveria de se levar em conta que o Brasil, à época do seu "descobrimento", era dominado pela comunidade primitiva, enquanto que no Ocidente europeu o feudalismo abria cada vez mais espaços para a nova sociedade que emergia da Revolução Comercial e das navegações oceânicas. Desta forma, a investigação do caso brasileiro comporta elementos não presentes nas análises dirigidas aos parses do Ocidente europeu.

Em segundo lugar, existe no Brasil áreas territoriais que vivenciam, a um só tempo, etapas históricas diversas e relaçöes sociais diferentes. Em grande medida esta díferenciação existe até hoje, mesmo levando-se em conta uma tendência à uniformidade imposta pela constituição da ordem burguesa no pais.

Em terceiro lugar se colocaria o fenômeno que ele considera como fato peculiar de uma colonização que se fez com base numa sociedade transplantada, totalmente diversa daquela com que se defrontaram os "descobridores". Assim sendo, nossa sociedade teve por base elementos transfericos da África e Europa. Os negros viriam constituir a massa de escravos, ou classe dominada; os europeus em grande maioria viriam ocupar o outro lado da balança, como proprietários, ou polo dominante.

A particularidade do caso brasileiro seria obvia: o escravismo no Brasil, ao contrário do exemplo clássico, não surgiu da comunidade primitiva; não houve evolução de um modo de produção para outro, ou de uma formação para outra. Para Werneck Sodré, não constitui preocupação estudar a comunidade primitiva indígena, visto que ela é secundária na sociedade brasileira fundada em elementos transplantados.

A forma de abordar o problema implicaria numa apresentação difarenciada do mesmo. Numa dimensâo universal, trataria-se de um processo de acumulação primitiva, porém, na dimensão sul-americana, do que se trata é de escravismo puro e simples.

Se o escravismo no Brasil não se origina da comunidade primitiva, ele surgirá de uma atividade comercial em que o trabalho escravo se colocava como

(*) Mestrando em Economia Rural - UFPb - Campus II

\begin{tabular}{|l|l|l|l|l|l|}
\hline Rev. RAIZFS & Campina Grande & Ano Vt & NO6 & 107 a 190 & Jan.86/mar.88 \\
\hline
\end{tabular}


mercadoria de grande valor, e constituindo a forma como foi possivel a colonização do Brasil. Contudo, Werneck Sodré dará pouco crédito ao fato de que no exterior se apropriava - via comercialização - uma parcela do excedente, desprezando-o como dado importante para analisar a sociedade brasileira fora de seus condicionamentos internos.

Analisando diversas áreas do território brasileiro, Sodré irá constatar que o escravismo não era o único modo de produção vigente no país, pois estava împlantado apenas naquelas regiôes em que se estabeleceu uma produção voltada para a exportação. Então ficaria uma pergunta no ar: e nas demais áreas, que modos de produção vigorariam? Investigando a área coletora amazônica e a área vicentina, os traços das relações sociais to elemento de sujeição religiosa, a produção de subsistência associada a uma produção destinada a um consumo externo) não the permitiram tirar conclusőes definitivas. Contudo, ele irá ver nas missões jesulticas uma identificação com o feudalismo.

O que transparece do texto de Sodré é que ele visualizava o feudalismo, ainda na época da colonização portuguesa, se espalhando por vastas áreas do território brasileiro, cercando aquelas regiões onde a produção era feita em larga escala, visando o mercado externo.

Refutando as críticas que imputam um certo esquematismo às suas formulações, Werneck Sodré oferecerá a sua tese de "regressão feudal": no modelo paradigmático, o feudalișmo representa um avanço em relação ao escravismo, porém, no caso brasileiro, o feudalismo - ou relações feudais - substituem as relações escravistas, como acontece com a área mineradora, no momento em que esta entre em declínio (em função da diminuição da quantidade de ouroproduzido), o que, do ângulo da riqueza produzida, representaria uma regressão.

Mas a grande polêmica, com que se defronta Sodré, é a da discussão sobre a existência de capitalismo no Brasil colonial. Para Sodré, a discusão tinha uma mistura de motivaçäo cientifica e política. Para os que, como ele, acreditavam na existência de relaçóes feudais ou semifeudais, pareceria coerente praticar uma polftica que visasse a eliminação destas relações como um primeiro passo para se chegar a uma nova fase de desenvolvimento social, o que implicava em completar a revolução burguesa, e alianças, para tanto, com a parcela nacional da burguesia interessada neste projeto. Já os que defendiam a tese do capitalismo, não aceitavam a idéia de se lutar por uma revolução burguesa para, só depoiș, colocar na ordem do dia a luta pelo socialismo.

Sodré irá explicitar os elementos com que trabalha para tirar as suas conclusỡes acerca da existência de relações feudais no Brasil : a renda e o laço de dependência social.

Fundamental para entender o caráter feudal predominante no campo, até os nossos dias, seria investigar as relações de dependência a que ficaram sujeitos os escravos após a Abolição, as formas como os serviços eram prestados, como as rendas eram pagas aos senhores da terra, etc. A maneira como fol se estabelecendo a posse da terra - marcadamente sob forma latifundiária - moldou o espaço próprio para que no Brasil se desenvolvesse relações feudais, ou semifeudais.

Para Sodré seria importante distinguir as relações feudais relacionadas aos primeiros tempos de nossa colonização, e que aqui se fizeram presentes por força 
da tradição lusa, das relaçōes feudais que surgiram da decomposição do escravismo, sendo implementadas em áreas onde antes dominavam as relações escravistas. Os núcleos escravistas foram assim substitu idos pelas relaçōes feudais, em função de sua decadência - como ocorreu com as plantações de açúcar e as zonas mineradoras - ou em função da abolição da escravatura.

Desta maneira, com a ampliação da dominação feudal no campo brasileiro, foi-se determinando como contradiçäo fundamental, a contradição entre senhores e servos, em função do que os entraves feudais significavam de obstáculos ao pleno desenvolvimento do capitalismo no Brasil.

O esquema teórico de Nelson Werneck Sodré, que ora reconstruímos, dá conta de uma visão que teve larga aceitação e divulgação no Brasil dos anos 50 e 60. Era a época em que se travava o debate acerca do "desenvolvimento nacional", melhor dizendo, do desenvolvimento capitalista num país que chegava a ele num momento em que os países capitalistas centrais (de modelo clássico) já possufam economias maduras, com fortes parques industriais e robustos mercados internos; um pais que possuía passado colonial e escravista e um setor agri. cola caracterizado, por um lado, pela agricultura de exportação às voltas com crises de superprodução, e por outro, pela agricultura voltada para o mercado interno que não dava conta da demanda por alimentos - uma agricultura que, de uma forma geral, empregava pouca tecnologia e apresentava relaçôes sociais atrasadas.

As teses de Werneck Sodré se situam dentro daquela corrente que se foi formando em oposição ao chamado dualismo estrutural que via no "nacionalismo estúpido" a causa do atraso e subdesenvolvimento do Brasil. A alternativa "progressista" via a raiz dos males brasileiros (identificados com o subdesenvolvimento) na ação de rapina do imperialismo e no parasitismo dos latifundiários. Mesmo com outro enfoque político, o desenvolvimento das teses progressistas partiam de um ponto comum com os dualistas: a existência de uma heterocronia característica de nossa sociedade, ou, como se dizia na época, a existência em nossa estrutura social de um setor urbano, dinâmico e moderno, e de outro, agrário, atrasado e incapaz de responder às necessidades de expansão capitalista.

Corroboravam com estas teses, sêtores liberais, a CEPAL, amplos setores de esquerda - destacando-se o PCB de Werneck Sodré - chegando mesmo, em um dado momento, a ter aceitação governamental, no perfodo de João Goulart.

Na medida em que Sodré não se desliga dessa tradição - o esforço de bus. car caminhos para que o capitalismo brasileiro atingisse a sua plenitude, ou seja, a insistência nos elementos caracter ísticos do capitalismo dos países de desenvolvimento clássico, não consegue questionar e combater a forma de desenvolvimento excludente e autoritário que começava a se esboçar já nos anos 50 e 60 e que resultou no modelo escolhido e posto em prática pelo regime militar que se seguiu a 1964. Justamente a política econômica deste foi responsável por jogar por terra as teorias que viam na "agricultura atrasada" um obstáculo ao desenvolvimento do capitalismo em nosso país, e que visualizavam contradições na burguesia nacional de tal monta que a faria se aliar às forças democráticas e nacionais, contrapondo-se ao imperialismo e aos latifundiários. Não só a burguesia brasileira se aliou ao imperialismo e ao latifúndio na sustentação do golpe (mostrando o verdadeiro sentido do desenvolvimento capitalista no Brasit, asso- 
ciado e dependente) como também o setor rural foi palco de uma modernização conservadora, modernização do latifúndio, via generosos subsídios estatais.

Há mais um ponto nas dificuldades do modelo de Sodré. O seu esforço de encontrar em Marx, elementos que fundamentem as suas análises, resulta infrutifero na medida em que em O Capital estará presente uma teoria abstrata do modo de produção capitalista, ou quando, num maior grau de concretude, exemplificando conceitos, Marx estará a se referir a elementos constitutivos da partitularidade européia, ou mais precisamente inglesa.

As imprecisões do esquema teórico de Sodré tem a ver com uma concepção evolucionista da história - suas análises vão se desenvolvendo no sentido de acompanhar uma seqüência de estádios ou modos de produção, prendendo-se a um modelo de desenvolvimento das sociedades do Ocidente europeu, de feitura clássica, o que não the permite visualizar as especificidades deste pal's atrasado, sim, mas capitalista, que se coloca numa situação de dependência ao sistema capitalista mundial, plenamente integrado a ele.

Nelson Werneck Sodré: "Modos de Produção no Brasil" em: José Roberto do A. Lapa (org):

Modos de Produção e Realidade Brasileira, Petrópolis - Vozes, 1988 